\title{
AN AHP-BASED APPROACH TO CREDIT RISK EVALUATION OF MORTGAGE LOANS
}

\author{
Fernando A. F. FERREIRA ${ }^{a, b, *}$, Sérgio P. SANTOS ${ }^{c, d}$, Vítor M. C. DIAS ${ }^{\text {e }}$ \\ a ISCTE Business School, University Institute of Lisbon, Avenida das Forças Armadas, 1649-026 \\ Lisbon, Portugal \\ ${ }^{b}$ Fogelman College of Business and Economics, University of Memphis, Memphis, TN 38152-3120, USA \\ ${ }^{c}$ Faculty of Economics, University of Algarve, Campus de Gambelas, 8005-139 Faro, Portugal \\ d CEFAGE, University of Évora, Portugal \\ e School of Management and Technology, Polytechnic Institute of Santarém, Complexo Andaluz, \\ Apartado 295, 2001-904 Santarém, Portugal
}

Received 3 July 2012; accepted 12 November 2012

\begin{abstract}
Mortgage loans for home purchase require careful analysis by all parties involved in the transaction, and credit-scoring is usually adopted to assist the decision process. From a credit institution standpoint, credit-scoring for mortgage loan risk evaluation becomes even more important in scenarios of economic turbulence and recession, primarily because of the severe restrictions imposed on credit availability that result from reduced access to both money and debt markets and subsequent decreasing liquidity. Employing an AHP - Analytic Hierarchy Process - based approach in the creditscoring system used by one of the major banks in Portugal, this study proposes a methodological framework conceived to adjust trade-offs among evaluation criteria and provide decision makers with a more transparent mortgage risk evaluation system. Practical implications of our framework are also discussed.
\end{abstract}

KEYWORDS: AHP-based approach; Credit-scoring; MCDA; Mortgage loan risk analysis; Trade-offs

REFERENCE to this paper should be made as follows: Ferreira, F. A. F.; Santos, S. P.; Dias, V. M. C. 2014. An AHP-based approach to credit risk evaluation of mortgage loans, International Journal of Strategic Property Management 18(1): 38-55.

\section{INTRODUCTION}

Different interlinked factors have been responsible for dramatically changing the current economic conjuncture worldwide. Directly or collaterally, the recent United States' subprime has been identified as the major cause for the declining values of real assets in many markets (cf. Yeager 2011; Kowalski, Shchmurove 2011; Puri et al. 2011; Wu 2012; Xiao-yan et al. 2011; Beltratti, Stulz 2012). For this particular reason, the relationship among financial and real estate markets, respective evolutionary trends and mortgage lending have been accompanied and/or studied with particular interest. This view seems to be further supported by

\footnotetext{
* Corresponding author. E-mail: fernando.alberto.ferreira@iscte.pt or fernando.ferreira@memphis.edu
}

Akhigbe and McNulty (2011: 532), who state that "the financial crisis of 2007-2009 was caused in part by weak incentives and poor lending decisions (...) in mortgage lending". In addition, because the purchase of a home is generally the largest investment for most households, together with the fact that most families fail to have the capital available to purchase a residence, mortgage in the form of bank lending is the most common solution for home acquisition. However, the current economic and financial conditions show not only increasing individual and corporate taxes, a generalized reduced employment rate and salary reductions but also reduced access to money and to medium- and long-term debt markets, leading banks to impose 
severe restrictions on access to credit. Consequently, each mortgage loan requires careful analysis by all parties involved in the decision process (e.g. individuals, families, credit institutions) and, under this scenario, "credit scoring benefits both lenders and borrowers" (Avery et al. 2004: 854).

In response to periods of economic turbulence and inherent decreasing liquidity, banks have developed sophisticated credit-scoring risk systems with the aim of "better quantifying the financial risks they face and assigning the necessary economic capital" (Lopez, Saidenberg 2000: 152). Based on this premise, significant improvements have occurred in terms of risk modeling (for a survey of developments and/or a generalized discussion, see Altman, Saunders 1997; Scarpel, Milioni 2002; Costa, Baidya 2003; Jacobson, Roszbach 2003; Avery et al. 2004; Yurdakul, İç 2004; Crook et al. 2007; Chikolwa, Chan 2008; Šušteršič et al. 2009; $\mathrm{Xu}$, Zhang 2009; Yu et al. 2009; Twala 2010; Wang et al. 2011) and, for the reasons presented above, mortgage lending risk evaluation has become increasingly important in the field of finance. Nevertheless, as shown in the literature (e.g. Altman, Saunders 1997; Lopez, Saidenberg 2000; Doumpos, Zopounidis 2001; Doumpos et al. 2002; Thomas 2009; Twala 2010), the progress achieved over the years does not mean that the current methodologies are without limitations and the need to develop more accurate credit-scoring systems has been put to rest. For example, particular emphasis has been given to the lack of transparency in the way trade-offs among evaluation criteria are made explicit (cf. Ferreira et al. 2011a). Thus, considering that MCDA - Multiple Criteria Decision Analysis - has proved over the years to be extremely effective in transparently incorporating multiple considerations into a decision making framework and in handling trade-offs among evaluation criteria (cf. Saaty 1980; Belton, Stewart 2002; Bana e Costa et al. 2005; Saaty 2008; among others), it is our belief that there is considerable scope to explore the applicability of MCDA techniques in the particular context of credit risk evaluation of mortgage loans, a topic which, following Mari and Renò (2005: 92), "is quite neglected in the financial literature".

In this paper, we analyze the internal system for assessing the credit risk in mortgage lending used by one of the largest banks in Portugal, and we employ an AHP - Analytic Hierarchy Process based approach in a structure of evaluation criteria previously defined by the bank's administration. It should be highlighted that several drawbacks can be identified in the current credit-scoring process, such as the way evaluation criteria are selected and/or made explicit. However, these limitations fall outside the scope of our study and, thus, will not be discussed here. On this basis, our empirical application aims to examine the potential value of the AHP approach in readjusting trade-offs among evaluation criteria, providing a better basis for the justification and explanation of decisions regarding mortgage lending and, ultimately, leading to a fairer mortgage risk evaluation system. To the best of our knowledge, this is a novel approach in the mortgage risk evaluation literature.

The paper proceeds as follows: the next section reviews existing literature on mortgage lending economic relevance. Section 3 describes the current credit-scoring system of the bank under analysis. Section 4 presents the methodological background and discusses the AHP-based proposal in terms of trade-offs readjustment, respective advantages and disadvantages. Finally, the paper concludes with section 5 .

\section{MORTGAGE LENDING ECONOMIC RELEVANCE}

Before the discussion on credit-scoring systems for mortgage loan risk evaluation, it seems opportune to discuss the economic importance of mortgage lending. In this sense, and as previously highlighted, home acquisition is generally the largest investment for most households, and because most families possess only a portion of the capital needed to buy a house, bank mortgage loans are the most typical (and perhaps easiest) solution. Therefore, mortgage lending has stimulated the economy over the years, and different interlinked reasons support this premise. Among these, it should be underlined that: (1) mortgage lending allows the expansion of financial services by supporting the development of the housing construction industry, which, in turn, supports the expansion of related business activities; (2) as result of the economic expansion, mortgage lending contributes to higher job growth rates and stimulates increased household consumption; and (3) mortgage loans increase money circulation among people, which, under wealth-generating economic conditions, contributes significantly to the country's GDP - Gross Domestic Product (for further details, see Lima et al. 1995; Mari, Renò 2005; Kajimo-Shakantu, Evans 2006).

According to Mari and Renò (2005: 83), "the market for mortgage loans is of primary impor- 
tance in any developed country, and its quality is directly connected to the quality of the whole economy". From this premise we conclude that, under wealth-generating economic conjunctures, mortgage lending has positive effects on the country's economy because it allows unemployment reduction, boosts productivity, increases money circulation and generates greater economic wealth (for further discussion, see also Lima et al. 1995; Kajimo-Shakantu, Evans 2006). Nevertheless, recalling Mari and Renò (2005), it should be taken into account that the relationship between mortgage lending and the country's economy is based on a reciprocal influence. This means that mortgage lending has no positive effects in slumping economies and, because of the generalized decreasing liquidity, mortgage loans should be analyzed with proper reservation.

\subsection{Mortgage loan risk evaluation}

Considering the decreasing liquidity and reduced access to both money and medium- and long-term debt markets that have been characterizing the current economic and financial conjuncture, mortgage loan risk evaluation is both a complex process and a very challenging undertaking. Based on this premise, banking institutions have been doing their best to develop effective ways of better quantifying the financial risks they face in each lending decision. In this context, a wide range of internal rating systems for credit-scoring has been developed in banking practice and can be found in the literature (for details, see Mari, Renò 2005). It seems important to bear in mind, however, that most of the credit-scoring systems developed for mortgage loan risk evaluation consider several administratively pre-established weighted criteria, which are the basis of the evaluation process and aim to support the final decision. Therefore, the development of internal rating systems is paramount for providing evidence in terms of credit decision support.

\subsection{Internal rating system for credit-scoring}

As outlined previously, credit-scoring represents the basis for loan approval, and "banks assign internal credit ratings to appraise the creditworthiness of their borrowers" (Grunert et al. 2005: 509). In this sense, banks' use of internal credit ratings have multiplied worldwide over the past decades, aiming to measure the risk of each credit transaction. The Portuguese financial and banking institutions are no exception and, in the particular context of mortgage lending, the most common evaluation criteria in the mortgage scoring systems include: (1) LTV - loan-to-value -, which balances the funding with the guarantee associated to the credit operation; (2) rate of effort, which represents the customer's capacity for paying the loan; (3) degree of involvement, which assumes a cross-selling perspective and provides information on the client's involvement with the bank (e.g. information on bank account average balance, existence of financial investments, credit cards and/or other existing banking products); (4) household, which provides information on the funds available to meet the primary needs of the client; (5) professional status, which considers knowledge of the client's current employment situation; and (6) customer's age, which is considered a key factor for the credit institution and for the insurance company that provides the guarantee. A more or less complex analysis of the above criteria results in either a "favorable" or "unfavorable" lending decision.

The mortgage scoring systems in Portugal tend to be standardized and the outcomes of each credit risk analysis are usually based on a scale ranging from " 1 " to " 10 " (i.e. " 1 " represents a very low-risk operation; "10" represents an extremely high-risk operation - this credit-scoring system is further explained in section 3), which also helps to determine the interest rate spread for each borrower. As a result of the precarious situation of the financial markets and all consequences associated in terms of decreasing liquidity, it becomes imperative for the banks' survival to impose severe mortgage lending underwriting requirements. These requirements include, among many others, the adoption of long term loans and reductions of the $L T V$ and rate of effort. Under this scenario, the associated spreads and indexed rates are also high, and often unaffordable to most potential borrowers.

\section{THE CURRENT CREDIT-SCORING SYSTEM}

As briefly mentioned in the previous section, the mortgage scoring systems in Portugal tend to be standardized and based on a continuous scale. This typically ranges from " 1 " to " 10 ", where a credit approval occurs when credit scores are between " 1 " and " 5 ", and a credit refusal takes place when scores are higher than " 5 ". It should be highlighted, however, that a potential borrower may score "1" and present very low-risk, but if for any reason the bank gets suspicious that s/he will not respect the required commitments, then the mortgage loan 
can be refused. Additionally, it should be clarified that the final outcome of a mortgage loan risk evaluation is usually a composite score, which is also known as overall score. The overall score is calculated through a weighted average of the partial scores obtained for each of the evaluation criteria taken into consideration in the risk assessment. Partial scores are based on a discrete scale ranging from "1" to "10" (cf. Appendix 1). The weights of the criteria reflect their relative importance and are usually defined by the bank's administration. In this sense, a very low-risk credit operation is associated to "1". Contrarily, an overall score of "10" represents an extremely high-risk credit operation. Overall scores strictly below "5" should support a credit approval. On the other hand, overall scores above " 5 " should support a credit refusal.

\subsection{Criteria and weights considered}

Banking institutions frequently innovate and modify the modalities of mortgage loans. Nevertheless, a battery of informal interviews with directors from the five largest banks in Portugal allowed us to conclude that the calculation of the risk associated with each mortgage loan usually relies on similar criteria. One of the interviewees, whose name has been kept confidential upon request, was particularly important in assisting us to understand how the composite scores result from the evaluation criteria and, specifically, to identify those criteria and respective trade-offs. Table 1 presents information on the criteria included in the mortgage risk evaluation system used by one of the top-five banks in Portugal, which has been provided under condition of anonymity.

As can easily be observed in Table 1 , the bank currently uses fourteen different criteria to assess mortgage lending, with the three most important criteria being $L T V$, rate of effort and responsibilities in $B P$ - Banco de Portugal - (Portuguese Central Bank after translation). Nonetheless, one of the interviewees (the director who provided us with the data) emphasized that the current weights do not adequately represent the relative importance of the criteria as perceived by the risk assessment experts operating in some of the branches, which sometimes results in incoherent decisions. For example, loan applications can be refused in spite of achieving overall scores below 5 . In order to prevent these incoherent decisions, it was felt by the group of experts involved in the study that the weight of some criteria (e.g. responsibilities in BP, cross-selling and existence of guarantors) should better reflect the values held by the credit-scoring experts. In
Table 1. Criteria and respective weights

\begin{tabular}{ll}
\hline Criteria & Weights \% \\
\hline Profession & 12.00 \\
Employment situation & 8.00 \\
Marital status & 3.75 \\
Age & 2.50 \\
Household & 3.75 \\
Cross-selling & 10.00 \\
Deposit portfolio & 2.50 \\
Average balances & 2.50 \\
Rate of effort & 15.00 \\
Responsibilities in BP & 15.00 \\
LTV & 15.00 \\
Existence of guarantors & 5.00 \\
Economic situation of the country & 2.50 \\
Political situation of the country & 2.50 \\
\hline
\end{tabular}

Source: Administrative information.

addition, it was also felt that some weight flexibility regarding the different criteria should be allowed across the country in order to capture idiosyncrasies of different geographic regions. As a result, it seems important to identify the major drawbacks of the current credit-scoring system. This will assist us in clarifying the evaluation mechanisms and, hopefully, introduce transparency in the process.

\subsection{Limitations of the current credit-scoring system}

As outlined before, the credit-scoring system for mortgage loans risk evaluation used by one of the largest banks operating in Portugal is not without its own limitations, and those limitations contribute to possible inconsistent conclusions that should be analyzed. According to the director who assisted us in understanding the process, different types of criticism can be pointed to the credit-scoring system currently in use by the bank. Among them, the following should be underlined: (1) "the system is unable to consider behavioral criteria" (quoting the director); (2) the weights are administratively predefined, but there is no prior knowledge of how the process is established, which makes it difficult to comprehend some of the decisions, due to the lack of transparency and/or rationality; and (3) considering that trade-offs among criteria are common to all bank branches, the possibility of inappropriate weighting becomes real because of the differences among geographic areas.

Starting out from these considerations, it should be clarified that the definition of new evaluation criteria falls outside the scope of this paper. As pre- 
viously stated, considering that MCDA has proved over the years to be extremely effective in transparently incorporating multiple considerations into a decision making framework and in handling trade-offs among criteria, it is our belief that there is considerable scope to explore the applicability of MCDA tools in the context of credit risk evaluation of mortgage loans. From this perspective, the following section describes how an AHP-based process can be applied in order to allow trade-offs readjustment among evaluation criteria, while considering the professional experience of bank experts. We believe that our process-oriented framework will result in a fairer and more transparent mortgage loan risk evaluation system.

\section{METHODOLOGICAL FRAMEWORK}

\subsection{Basics of the Analytic Hierarchy Process}

As indicated in the previous sections, credit risk analysis of mortgage loans implies taking into account several criteria and analyzing decisions with transparency. From this perspective, the risk evaluation process of mortgage lending can profit from the application of MCDA tools, namely because it is well known that these tools facilitate the tradeoffs calculation among criteria, while adding simplicity and transparency to the decision making process (cf. Belton, Stewart 2002; Ferreira et al. 2011a).

The AHP is a multiple criteria decision analysis technique that was developed by Thomas Saaty, in the mid-1970s, in order to overcome the cognitive limitations of decision makers (cf. Saaty 1980). Based on its simplicity, solid mathematical background and ability to assess tangible or intangible factors, the method has been applied to systematize a wide range of decision problems in different contexts. In particular, the method is based on the human capacity to use information and experience in estimating relative magnitudes through pairwise comparisons and, basically, combines logic with intuition, for the purpose of obtaining consensual judgments (for further details, see Saaty 2008; Pastor-Fernando et al. 2010; Kaya, Kahraman 2011).

According to Yurdakul and İç (2004), who applied the AHP in the evaluation of credit applications of manufacturing firms, the application of the method can be divided into three main phases: structuring, evaluation and synthesis. The first phase - structuring - consists of decomposing the problem into a hierarchical structure that reveals the relationship between goals, criteria and alternatives involved in the decision process (see Fig. 1).

The second phase - evaluation - consists of defining the type of problem to be adopted and determining if the alternatives/actions should be: a) analyzed in relative or absolute terms, b) ordered or chosen or c) accepted or rejected. Finally, the last phase - synthesis - consists of providing an overall score and recommendations. In order for evaluation and synthesis to take place, decision makers have to compare pairs of criteria and sub-criteria (if any). The pairwise comparisons expressed in semantic judgments are then converted into numerical values. This is done based on a onedimensional scale, known as 'Saaty's fundamental scale', where judgments of quantification range from 1 to 9 (see Table 2).

This procedure will result in the construction of square matrices of preferences, where the number in row $i$ and column $j$ gives the importance of a certain criterion $C_{i}$ in comparison to another criterion $C_{j}$, as can be seen in the matrix form (1) shown below.

$$
A=\left[a_{i j}\right]=\left[\begin{array}{lcccc}
1 & a_{12} & a_{13} & \ldots & a_{1 j} \\
1 / a_{12} & 1 & a_{23} & \ldots & a_{2 j} \\
1 / a_{13} & 1 / a_{23} & 1 & \ldots & a_{3 j} \\
\ldots & \ldots & \ldots & 1 & \ldots \\
1 / a_{1 j} & 1 / a_{2 j} & 1 / a_{3 j} & \ldots & 1
\end{array}\right] .(1)
$$

More specifically, following Alonso and Lamata (2006), let $A=\left[a_{i j}\right]$ for all $i, j=1,2, \ldots, n$ denote a square pairwise matrix, where $a_{i j}$ gives the relative importance of the elements $i$ and $j$, and is represented by a quantified value judgment provided by the decision makers, which also helps to define $\alpha$ as the corresponding value of intensity of importance. According to Vilas Boas (2005), this technical procedure must respect the following conditions (2):

$$
\left\{\begin{array}{l}
\text { If } a_{i j}=\alpha, \text { then } a_{j i}=1 / \alpha, \alpha \neq 0 \\
\text { If } C_{j} \text { is considered as equaly relevant as } C_{j}, \\
\text { then } a_{i j}=1, a_{j i}=1 \text { and } a_{i i}=1, \forall i
\end{array}\right.
$$

At this stage, the matrices of comparison are subjected to a mathematical technique called eigenvector, which calculates the weights $w$ for each criterion in the various hierarchical levels and in relation to the alternatives under consideration. The eigenvector matrix can be estimated by the mathematical expression (3):

$$
W_{i}=\left(\prod_{i=1}^{n} a_{i j}\right)^{1 / n} .
$$




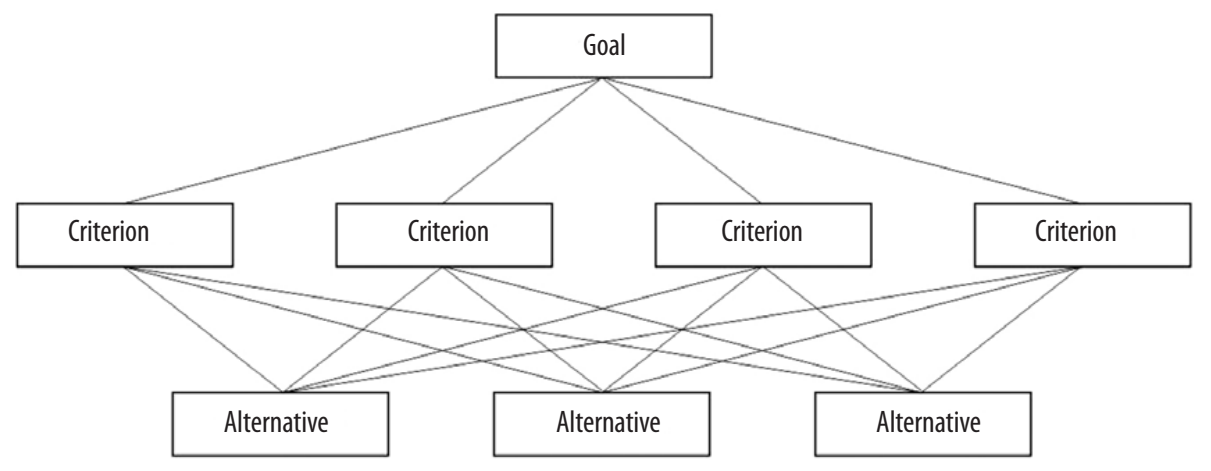

Fig. 1. AHP conceptual structure Source: Saaty (2008, adap.).

Table 2. Fundamental scale of absolute numbers

\begin{tabular}{|c|c|c|}
\hline Intensity of Importance & Definition & Explanation \\
\hline 1 & Equal importance & Two activities contribute equally to the objective \\
\hline 2 & Weak or slight & \\
\hline 3 & Moderate importance & $\begin{array}{l}\text { Experience and judgment slightly favor one activity } \\
\text { over another }\end{array}$ \\
\hline 4 & Moderate plus & \\
\hline 5 & Strong importance & $\begin{array}{l}\text { Experience and judgment strongly favor one activ- } \\
\text { ity over another }\end{array}$ \\
\hline 6 & Strong plus & \\
\hline 7 & $\begin{array}{l}\text { Very strong or demonstrated } \\
\text { importance }\end{array}$ & $\begin{array}{l}\text { An activity is favored very strongly over another; its } \\
\text { dominance demonstrated in practice }\end{array}$ \\
\hline 8 & Very, very strong & \\
\hline 9 & Extreme importance & $\begin{array}{l}\text { The evidence favoring one activity over another is of } \\
\text { the highest possible order of affirmation }\end{array}$ \\
\hline $1.1-1.9$ & $\begin{array}{l}\text { When activities are very close a deci- } \\
\text { mal is added to } 1 \text { to show their differ- } \\
\text { ence as appropriate }\end{array}$ & $\begin{array}{l}\text { A better alternative way to assigning the small deci- } \\
\text { mals is to compare two close activities with other } \\
\text { widely contrasting ones, favoring the larger one a lit- } \\
\text { tle over the smaller one when using the } 1-9 \text { values. }\end{array}$ \\
\hline Reciprocals of above & $\begin{array}{l}\text { If activity } i \text { has one of the above } \\
\text { nonzero numbers assigned to it when } \\
\text { compared with activity } j \text {, then } j \text { has } \\
\text { the reciprocal value when compared } \\
\text { with } i\end{array}$ & A logical assumption \\
\hline $\begin{array}{l}\text { Measurements from ra- } \\
\text { tio scales }\end{array}$ & & $\begin{array}{l}\text { When it is desired to use such numbers in physical } \\
\text { applications. Alternatively, often one estimates the } \\
\text { ratios of such magnitudes by using judgment }\end{array}$ \\
\hline
\end{tabular}

Source: Saaty (2008: 257).

As defended by Laininen and Hämäläinen (2003) and Vilas Boas (2005), among others, the results obtained using this mathematical expression must be standardized. The process consists in calculating the proportion of each element relative to the sum, as can be observed in the expression (4), where $T$ is the normalized eigenvector:

$$
T=\left|W_{1} / \sum W_{i} \ldots W_{n} / \sum W_{i}\right| .
$$

This procedure results in the eigenvector ordering of priorities and is repeated until the difference between the normalized result of the last operation is very close to the result of the preceding case (e.g. small differences after third decimal place). The eigenvector provides a hierarchy or priority order for the criteria, and the quality or consistency of the solution must be tested by calculating the eigenvalue, which indicates whether the data are 
logically related. For this purpose, Saaty (2008) proposes the following sequence of procedures:

- Estimate the eigenvalue $\left(\lambda_{\max }\right)$ through expression (5), where $w$ is calculated by summing the columns of the matrix of comparisons:

$\lambda_{\text {max }}=T . w$.

- Compute the consistency index - CI through equation (6), where $n$ stands for the order of the matrix:

$C I=\frac{\lambda_{\max }-n}{n-1}$.

- Calculate the consistency ratio - CR - using equation (7), where RI is a random consistency index and depends on the order of the matrix (for a compilation of RIs from different authors, see Alonso, Lamata 2006). The literature usually considers CR as an acceptable consistency ratio when its value is below 0.10 (cf. Saaty 1980; Yurdakul, İç 2004; Williams et al. 2007; Xu, Zhang 2009; PerezGladish, M'Zali 2010). CR values greater than 0.10 suggest a revision of the matrix of comparisons:

$C R=C I / R I$.

To determine the levels of preference of the alternatives, they should be compared in pairs in each of the criteria, following a similar procedure to the one described for obtaining the relative importance of criteria. With these levels and the relative importance of preference of the alternatives, an overall assessment for each alternative can be made explicit based on the additive model expressed by equation (8), where $V(a)$ corresponds to the overall value of the alternative analyzed; $p j$ is the relative importance of criterion $j$ and $v j$ is the level of preference of the alternative analyzed in criterion $j$ :

$$
\begin{aligned}
& V(a)=\sum_{j=1}^{n} p_{j} v_{j}(a) \text { with } \sum_{j=1}^{n} p_{j}=1 \\
& \text { and } 0<p_{j}<1(j=1, \ldots, n) \text {. }
\end{aligned}
$$

\subsection{Strengths and weaknesses of the AHP}

As in other methods, the AHP has strengths and weaknesses. An extensive discussion on its advantages and shortcomings is beyond the scope of the present study. However, it should be highlighted that the AHP has been characterized as simple, solidly supported on mathematical background and able to assess quantitative and qualitative factors. In particular, one of the most significant strengths of the AHP results from the fact that it requires individuals to make comparisons only between pairs of alternatives (cf. Vilas Boas 2005; Saaty 2008). Moreover, the ability to measure the degree of inconsistency present in pairwise judgments and ensure that only justifiable orders are used as the basis for assessments have also been reported in the literature (e.g. Yurdakul, İç 2004; Vilas Boas 2005; Perez-Gladish, M'Zali 2010).

On the other hand, different types of criticism have been raised and, as defended by Williams et al. (2007: 470), "its theoretical foundation has been challenged on a number of grounds". For example, the AHP has been criticized for the possibility of exhibiting rank reversal (Belton, Gear 1983), and for its use of the eigenvalue procedure to derive priorities (Bana e Costa, Vansnick 2008). Also, as stated by Alonso and Lamata (2006: 448), "if the prioritization procedure is not the eigenvalue method (EVM), because of the way that the Saaty approach is constructed, it is not suitable for evaluating consistency, and therefore new consistency measures relating to the prioritization procedure are required".

It is important to underline, however, that in recent years important advances have been made (e.g. Alonso, Lamata 2006) and, according to PerezGladish and M'Zali (2010: 109), "several works can be found in the literature relating AHP with $\mathrm{fi}$ nance". Nevertheless, to the best of our knowledge, no evidence has been reported exploring the use of this method in the particular context of the present study. Therefore, we believe the AHP-based application we discuss in the next subsection, and which is targeted at showing how this technique can be used to define the trade-offs among the criteria used to assess credit risk in mortgage lending, is of interest to both researchers and practitioners.

\subsection{Readjusting trade-offs among criteria in internal ratings of credit-scoring}

As previously outlined, we describe in this subsection the process followed in terms of trade-offs readjustment in a mortgage loan credit-scoring system. Considering the limitations presented in subsection 3.2, it should also be emphasized that this research was conducted after the ECB-EUIMF intervention (i.e. European Central Bank, European Union and International Monetary Fund intervention, also known as "Troika"), which required the mortgage loan approval process to be 
more meticulous and discerning. On this basis, and considering the scope of our study, several aspects will be presented and/or discussed herein, namely: participants involved; problem definition; structuring and evaluation procedures undertaken; consistency and sensitivity analyses; and results discussion and recommendations.

\subsubsection{Participants involved}

It is well known that one of the features of the MCDA approach is an active attitude from decision makers (cf. Ferreira et al. 2011b), who are responsible for assisting the facilitator (i.e. researcher or scientist) in conceiving the evaluation system. Therefore, and because the definition of a panel of experts is considered an important procedure, the dimension of the panel was carefully considered in our study, along with two other intertwined constrains: (1) limited availability of mortgage loan risk analysts to participate in group meetings and (2) difficulties in getting them together in the same place at the same time. As a result, we ended up with a group formed by five credit analysts with mortgage loan risk evaluation responsibilities who operate in the same geographic region. In addition, it should be pointed out that the work session was conducted by a senior facilitator assisted by a junior facilitator and a communication technician, responsible for registering the results.

\subsubsection{Problem definition}

In response to the limitations identified in subsection 3.2 of the internal system for credit-scoring of mortgage loan applications used by the bank under analysis, namely in terms of trade-offs among evaluation criteria, our framework aims to employ an AHP-based approach in a structure of administratively pre-established evaluation criteria. It should be outlined, however, that we were not asked (nor allowed) to change the credit-scoring system in terms of criteria selection and/or operational structure (see Appendix 1). Instead, we were limited to the analysis of the trade-offs among the pre-selected evaluation criteria. In this sense, although the different criteria had been administratively imposed, on the whole it was felt that the use of a MCDA approach would provide more structure to the decision-making process, a forum for discussion and learning and, in sequence, a better basis for the justification and explanation of decisions regarding the approval of mortgage loans. We believe this will add value to the risk evaluation process of mortgage loans, increase its effectiveness and lead to a fairer mortgage risk evaluation system. Start- ing out from this initial premise, the analysis of the problem consists of eliciting value judgments from a panel of credit analysts and readjusting tradeoffs among those administratively pre-established criteria (see Table 1), which are considered the basis of the evaluation process and aim to support the lend or reject decision. Moreover, as previously stated, this also represents a novel approach in the credit-scoring literature.

\subsubsection{Evaluation criteria and impact levels}

Following the previous discussion, several drawbacks can be pointed to the credit-scoring process currently used by the bank under analysis, namely the way evaluation criteria are selected and incorporated in the model. However, considering that we were not asked (nor allowed) to change the credit-scoring system in terms of the evaluation criteria to use to assess credit risk, the selection process of these criteria will not be discussed here. Instead, our objective is to discuss the potential of using the AHP technique to deal with the tradeoffs among the pre-established evaluation criteria. As outlined in the previous subsection, our empirical application aims to examine the potential value of the AHP approach in readjusting tradeoffs among evaluation criteria and, ultimately, lead to a fairer mortgage risk evaluation system. Based on the information provided in Table 1, Fig. 2 illustrates the structure of criteria that supports mortgage lending risk evaluation at the bank under analysis.

The structure presented in Fig. 2 allows us to identify two different decision levels. The first is based on a discrete scale ranging from " 1 " to " 10 ", representing impact levels for each of the criteria involved. In this case, the levels are administratively defined and a partial credit approval occurs when credit scores are between " 1 " and " 5 ", while a partial credit refusal takes place when the scores are between "6" and "10" (for a categorized information on this technical procedure, see Appendix 1). The second level is directly related to the overall score of each mortgage loan application, when the partial scores in each criterion are weighted by their relative importance. These overall scores are measured on a continuous scale ranging from "1" to " 10 ". Based on the reasons presented before, it is precisely here that we believe that there is considerable scope to explore the applicability of the AHP approach. It should also be underlined that the conceptual scheme presented in Fig. 2 was shown to the experts and considered important to establish the basis for a proper elicitation of judgments. 


\subsubsection{Judgments and comparisons}

This phase of the process was initiated based on a matrix of comparisons to order the criteria presented in Fig. 2. More specifically, the panel members were asked to pairwise compare and order the evaluation criteria in terms of decreasing overall importance. This procedure served as the basis for the projection of priorities and lasted approximately one hour. The next step consisted of the calculation of the trade-offs among criteria.

\subsubsection{The trade-off procedures}

Once the criteria were ordered by decreasing overall importance, the panel members were asked to project their judgments in terms of relative importance using 'Saaty's fundamental scale' (Table 2). This procedure lasted another hour. Fig. 3 illustrates the questionnaire of pairwise comparisons, which was constructed using the Super Decisions software (http://www.creativedecisions.net/). Table 3 summarizes the results obtained.

Once the "new" trade-offs were obtained, they were provided to the decision makers. This procedure was considered important to promote further discussion among the panel members and allow comparisons between both models (i.e. between the bank's current model and the AHP-based model). As can be seen from Table 3, the new criteria weights, which reflect the relative importance of each criterion as perceived by the credit analysts involved in our study, present some significant differences regarding the administratively imposed weights. Whilst the relative importance of some criteria remained relatively unchanged (e.g. age, household, rate of effort and LTV), the weight given to others changed significantly (e.g. existence of guarantors, employment situation, profession and average balances). It was agreed by the group of experts that these "new" weights have the potential to lead to different but better informed and supported decisions regarding mortgage lending in comparison to the current evaluation system. In addition, it should be highlighted that our results present an acceptable consistency ratio (i.e. $0.026412<0.10$ ) (cf. Saaty 1980; Yurdakul, İç 2004; Williams et al. 2007; Xu, Zhang 2009; PerezGladish, M'Zali 2010). The next step consisted of testing the "new" trade-offs.

\subsubsection{Evaluating mortgage loan credit risk}

Following the previous discussion, credit-scoring allows us to calculate scores between " 1 " and "10". As presented in formulation (8), the final score corresponds to the sum of the partial weighted scores. A score between " 1 " and " 5 " should support a favorable credit decision. From this basis, informa-

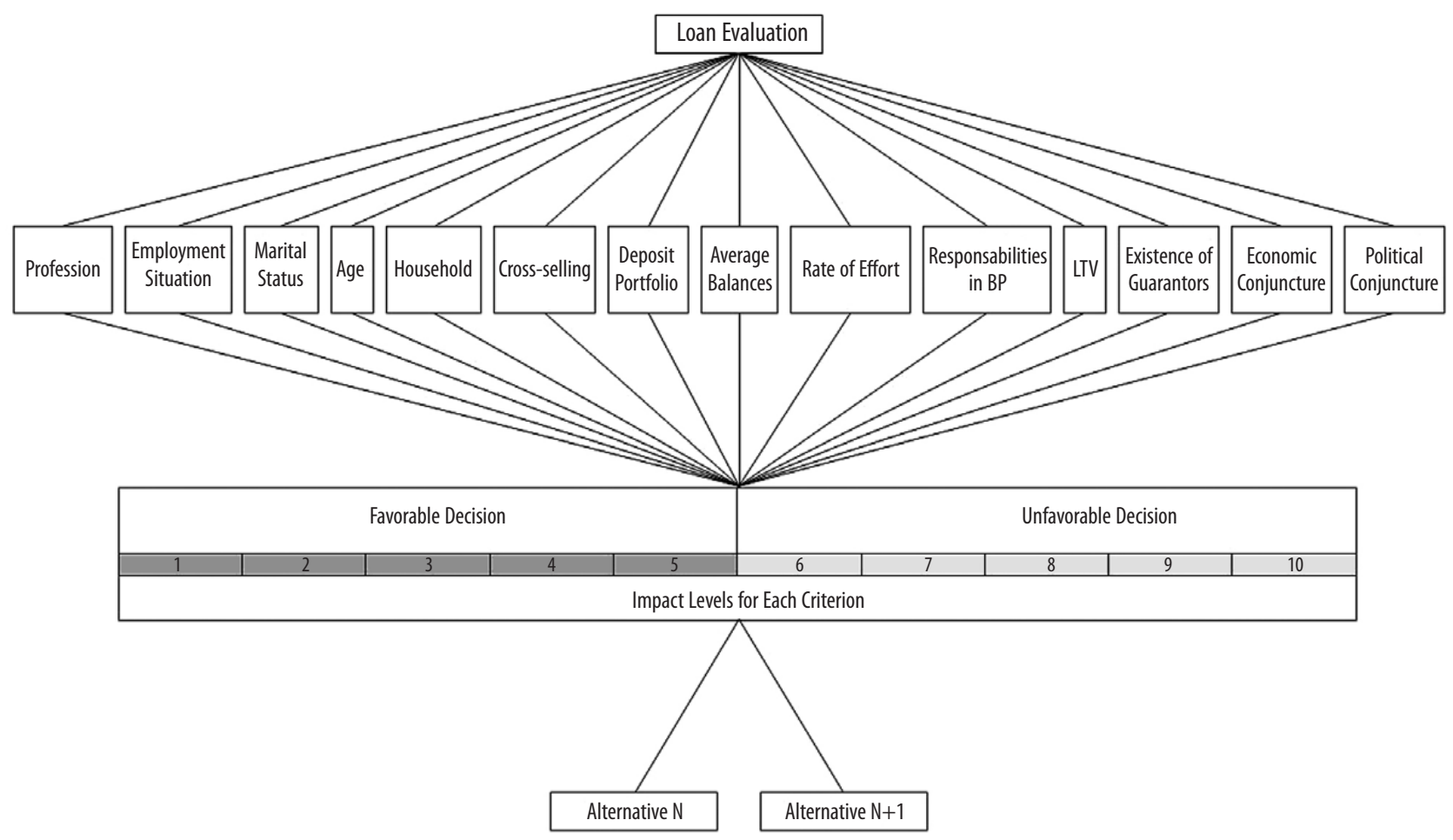

Fig. 2. Structure of evaluation criteria and respective impact levels Source: Own elaboration (based on administrative information). 


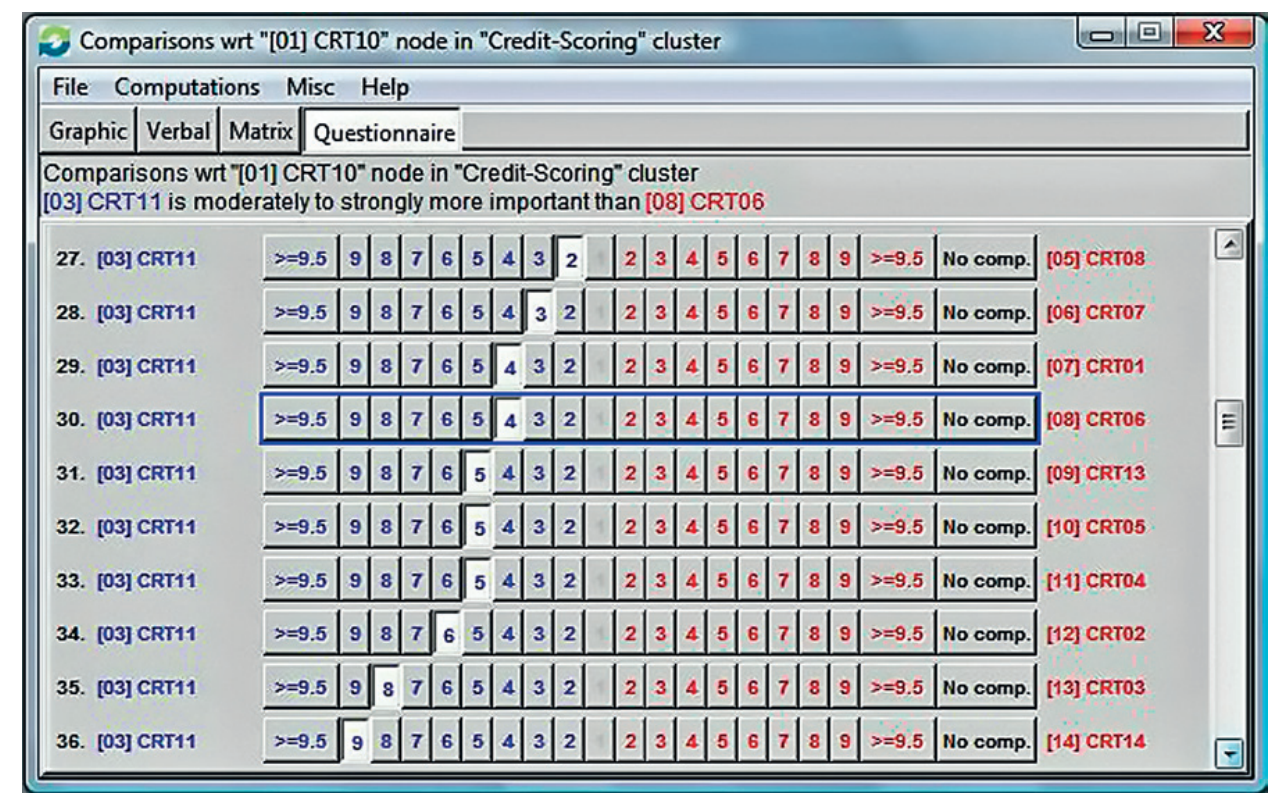

Fig. 3. Questionnaire of judgments [Super Decisions software]

Table 3. Criteria ranking and "new" trade-offs

\begin{tabular}{lllll}
\hline Criteria & Nomenclature & Ranking & (New) Weights \% & D \% \\
\hline Profession & CRT01 & 7 & 5.79 & -6.21 \\
Employment situation & CRT02 & 12 & 1.74 & -6.26 \\
Marital status & CRT03 & 13 & 1.38 & -2.37 \\
Age & CRT04 & 11 & 2.10 & -0.40 \\
Household & CRT05 & 10 & 2.80 & -0.95 \\
Cross-selling & CRT06 & 8 & 4.66 & -5.34 \\
Deposit portfolio & CRT07 & 6 & 7.44 & +4.94 \\
Average balances & CRT08 & 5 & 15.68 & +6.18 \\
Rate of effort & CRT09 & 2 & 19.30 & +0.97 \\
Responsibilities in BP & CRT10 & 1 & 14.04 & +4.30 \\
LTV & CRT11 & 3 & 11.59 & -0.96 \\
Existence of guarantors & CRT12 & 4 & 3.37 & +6.59 \\
Economic situation of the country & CRT13 & 9 & 1.14 & -1.36 \\
Political situation of the country & CRT14 & 14 & 0.87 \\
\hline
\end{tabular}

tion regarding mortgage loan applications, identified as "alphas", was provided under anonymous conditions upon request (see Table 4).

It should be noted that the data provided regarding (only) two mortgage loan applications was an administrative decision. Still, this information was considered very useful and necessary to know how the bank obtains the partial ratings, which vary between " 1 " and "10", and are based on the information provided in Appendix 1. Table 5 presents the partial ratings of the two alphas in analysis, criteria weights in both scenarios and overall scores.

Considering the information in Table 5, one may conclude that both models indicate possible approval of the credit applications under analysis (i.e. in both cases, Alpha 1 and Alpha 2 perform between " 1 " and " 5 "). However, considering the current evaluation model, significant adjustments have been made resulting from the use of the AHP-based approach. For example, in spite of the low importance given to the existence of guarantors in the current evaluation model (i.e. 5\%), this criterion was considered by the decision makers as one of the most important guarantees for the bank in case of credit default. This allowed them to rank the existence of guarantors in fourth place and adjust its weight (i.e. $11.59 \%$ ). According to the decision makers involved in our study, the adjustments made represent "more caution in terms 
of credit approval", which corroborates with the Basel directives. The next step consisted of performing consistency and sensitivity analyses to the calculi made.

\subsubsection{Consistency and sensitivity analyses}

Once the trade-offs among evaluation criteria were readjusted, tested, discussed and approved by the panel members, several consistency and sensitivity analyses were conducted. Fig. 4 illustrates a consistency analysis carried out with the Super Decisions software.

As previously outlined, our results present a consistency ratio of 0.026412 , which, according to the literature (cf. Saaty 1980; Yurdakul, İç 2004; Williams et al. 2007; Xu, Zhang 2009; PerezGladish, M'Zali 2010), is considered acceptable. However, the consistency analysis carried out during the group session allowed decision makers to discuss possible adjustments in terms of value

Table 4. Data from two anonymous customers

\begin{tabular}{lll}
\hline & Alpha 1 & Alpha 2 \\
\hline Profession & $\begin{array}{l}\text { Customer with a profession in a } \\
\text { stable industry }\end{array}$ & $\begin{array}{l}\text { Customer with a profession in a stable } \\
\text { industry }\end{array}$ \\
Employment status & $\begin{array}{l}\text { Customer with three years of per- } \\
\text { manent employment }\end{array}$ & $\begin{array}{l}\text { Customer with sixteen years of permanent } \\
\text { employment }\end{array}$ \\
Marital status & Single & Married \\
Age & $25-35$ & $36-50$ \\
Household & 1 Element & 4 Elements \\
Cross-selling & Customer who holds a single bank & Customer who holds several financial \\
& account and households his/her & products and households his/her salary in \\
& salary & the institution \\
Average balance & {$[0-1.000 €]$} & $>2.500 €$ \\
Deposit portfolio & {$[2.500 €-25.000 €[$} & {$[25.000 €-50.000 €]$} \\
Rate of effort & $34,60 \%$ & $41,40 \%$ \\
Responsibilities in BP & Without other responsibilities & Without other responsibilities \\
LTV & $77,78 \%$ & $53,16 \%$ \\
Existence of guarantors & No & No \\
Economic situation of the country & Stable with difficulties & Stable with difficulties \\
Political situation of the country & Stable & Stable \\
\hline
\end{tabular}

Source: Administrative information

Table 5. Partial and overall scores

\begin{tabular}{|c|c|c|c|c|c|c|}
\hline & \multicolumn{3}{|l|}{ Alpha 1} & \multicolumn{3}{|l|}{ Alpha 2} \\
\hline & $\begin{array}{l}\text { Partial } \\
\text { score }\end{array}$ & $\begin{array}{l}\text { Current } \\
\text { weight \% }\end{array}$ & $\begin{array}{l}\text { AHP } \\
\text { weight \% }\end{array}$ & $\begin{array}{l}\text { Partial } \\
\text { score }\end{array}$ & $\begin{array}{l}\text { Current } \\
\text { weight \% }\end{array}$ & $\begin{array}{l}\text { AHP } \\
\text { weight \% }\end{array}$ \\
\hline Profession & 3 & 12.00 & 5.79 & 3 & 12.00 & 5.79 \\
\hline Employment status & 2 & 8.00 & 1.74 & 1 & 8.00 & 1.74 \\
\hline Marital status & 1 & 3.75 & 1.38 & 1 & 3.75 & 1.38 \\
\hline Age & 2 & 2.50 & 2.10 & 4 & 2.50 & 2.10 \\
\hline Household & 1 & 3.75 & 2.80 & 4 & 3.75 & 2.80 \\
\hline Cross-selling & 4 & 10.00 & 4.66 & 2 & 10.00 & 4.66 \\
\hline Deposit portfolio & 4 & 2.50 & 7.44 & 3 & 2.50 & 7.44 \\
\hline Average balance & 3 & 2.50 & 8.68 & 1 & 2.50 & 8.68 \\
\hline Rate of effort & 2 & 15.00 & 15.97 & 2 & 15.00 & 15.97 \\
\hline Responsibilities in BP & 1 & 15.00 & 19.30 & 1 & 15.00 & 19.30 \\
\hline LTV & 4 & 15.00 & 14.04 & 3 & 15.00 & 14.04 \\
\hline Existence of guarantors & 6 & 5.00 & 11.59 & 7 & 5.00 & 11.59 \\
\hline Economic situation of the country & 4 & 2.50 & 3.37 & 4 & 2.50 & 3.37 \\
\hline Political situation of the country & 3 & 2.50 & 1.14 & 3 & 2.50 & 1.14 \\
\hline Overall score $\left({ }^{*} \mathrm{CR}=0.026412\right)$ & - & 2.745 & $2.975^{*}$ & - & 2.453 & $2.718^{*}$ \\
\hline
\end{tabular}



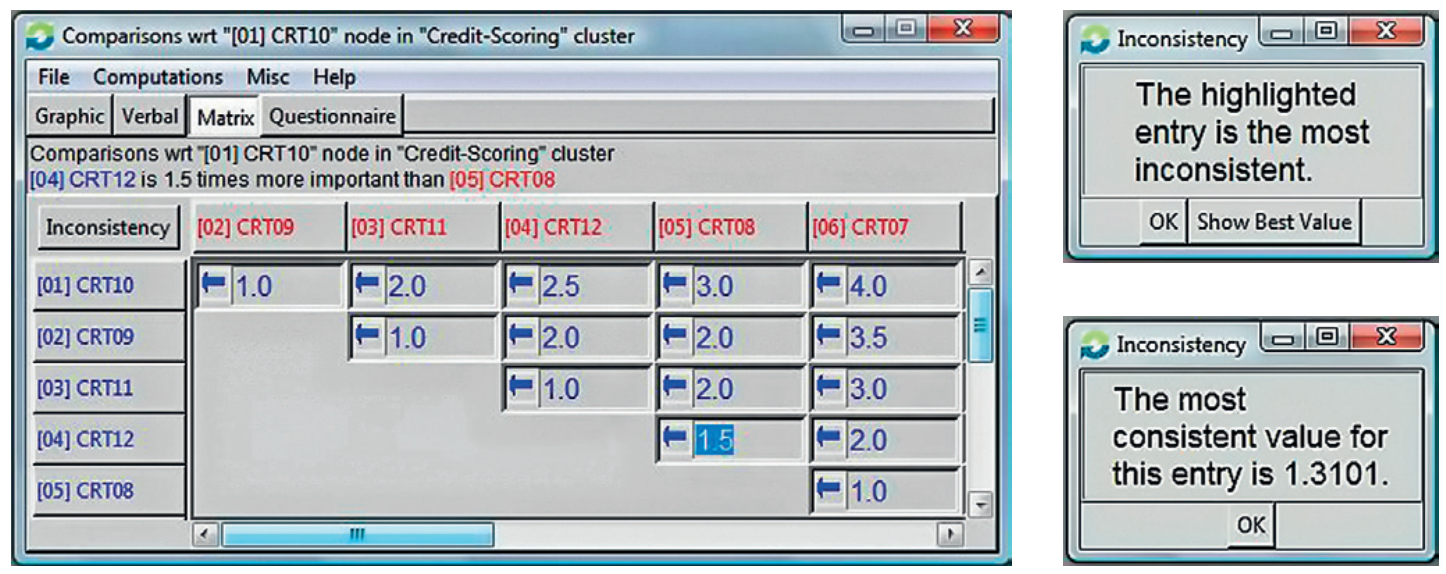

Fig. 4. Consistency analysis

judgments and, consequently, criteria trade-offs. As shown in Fig. 4, the most inconsistent judgment occurred between CRT12 (i.e. existence of guarantors) and CTR08 (i.e. average balances), and was of (very) small amplitude (i.e. 1.5 vs. 1.3101). In spite of the small difference identified, the usefulness of the Super Decisions software in offering opportunities for panel members to reconsider their value judgments should be highlighted. After discussion, the decision makers decided not to introduce further adjustments and considered the final tradeoffs as good representations of their value judgments. At this stage, it was considered useful to explore the sensitivity of the results obtained by each credit application by performing a sensitivity analysis. Fig. 5 presents the sensitivity analyses carried out for CRT07 (exemplifying non-crossing situations) and CRT12 (exemplifying crossing situations), which were conducted also using the Super Decisions software.

Despite the low number of alphas used for testing the model, the sensitivity analysis allowed us to explore the implications of uncertainty regarding the weights of the evaluation criteria, increasing confidence in the results achieved. More specifically, the analysis revealed that eleven out of the fourteen criteria show non-crossing lines between the alphas' partial performances (i.e. only CRT04, CRT05 and CRT12 revealed crossing lines), meaning that each alpha would maintain its relative ranking position independently of the weight given to each criteria. In this sense, as exemplified in Fig. 5, the intervals of weight variation are large enough to ensure that the alphas' ranking position remains even when the relative weight of criteria changes, supporting the value judgments of the credit experts.

The results of the consistency and sensitivity analyses were therefore important to: (1) validate the results in terms of trade-offs and explore the robustness of the recommendations generated by the multiple criteria framework; (2) promote additional discussion among the credit experts; and (3) define the basis for recommendations.

\subsubsection{Overall analysis and recommendations}

Based on the satisfaction shown by the panel members, one may consider that our results are encouraging. In fact, our AHP-based application allowed readjustment of trade-offs among criteria, and provided the panel experts with "a more informed, transparent and accurate mortgage loan risk evaluation system" (according to their own words). Furthermore, quoting the experts, our proposal was also considered "more discerning in terms of Basel directives", which strengthens our research convictions. Despite the results, it should be recalled, however, that a non-prescriptive process-oriented position has always been assumed. Consequently, our proposal should be viewed as a learning mechanism resulting from the discussion with and among the panel members, and not as a tool to provide optimal solutions. In this sense, because the results are contextualized and dependent on the participants involved, extrapolations are strongly discouraged unless proper adjustments take place. This may be considered another positive aspect of our framework because the use of AHP provides decision makers with adjustment possibilities.

\section{CONCLUDING REMARKS}

In periods of economic turbulence like the one financial institutions are currently experiencing, where liquidity is scarce and access to money and/ or to medium- and long-term debt markets is very limited, severe restrictions on access to credit are 


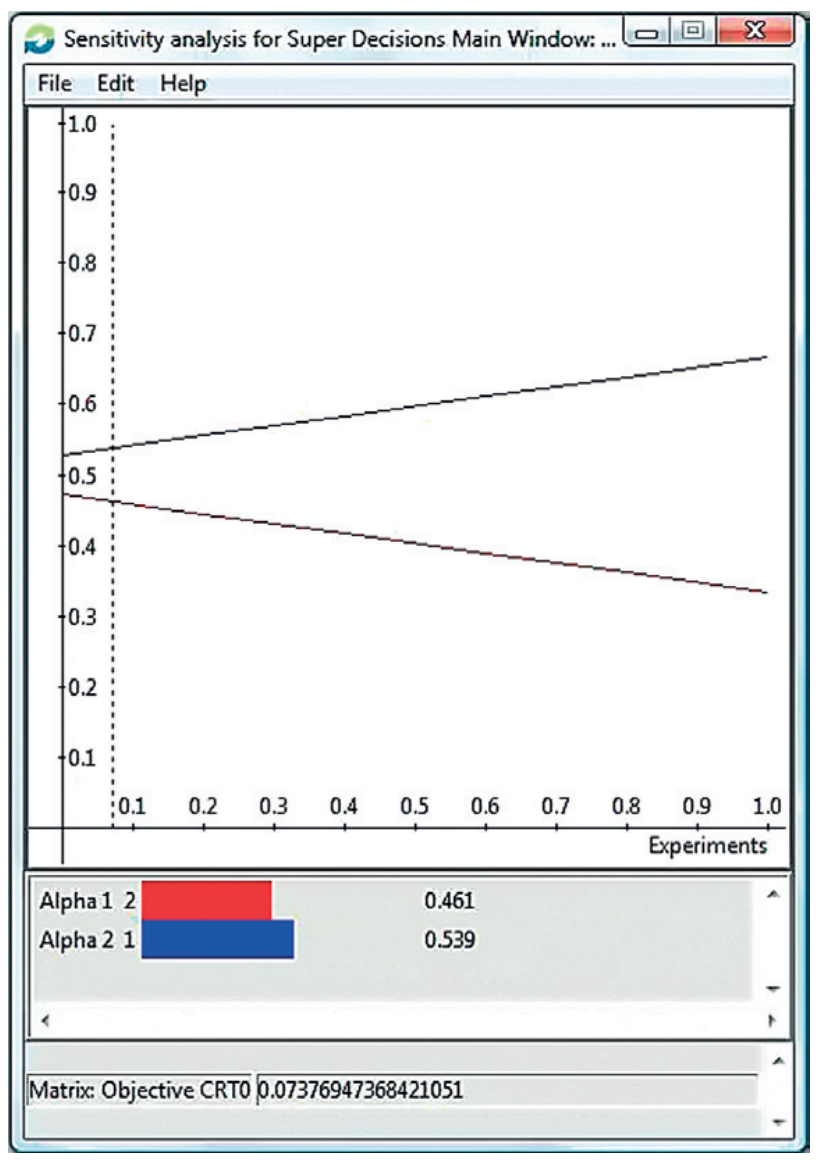

Fig. 5. Sensitivity analysis [CRT07 (left) and CRT12 (right)]

imposed. Mortgage loans are among the most highly sought financial products in the Portuguese banking system, but even those need to be carefully analyzed by all parties involved in the decision process. This means that, accompanied by higher credit underwriting standards, mortgage loan risk evaluation becomes imperative for financial and banking institutions.

As discussed herein, significant improvements have occurred over the last few decades in terms of risk modeling. Nevertheless, as stated in the literature (e.g. Altman, Saunders 1997; Lopez, Saidenberg 2000; Doumpos, Zopounidis 2001; Doumpos et al. 2002; Thomas 2009, 2010; Twala 2010), the progress achieved over the years does not mean that the current methodologies are without limitations and the need to develop more accurate creditscoring systems has been put to rest. In this particular context, special emphasis has been given to the lack of transparency in the way trade-offs among criteria are usually defined (cf. Ferreira et al. 2011a, 2011c). From this premise, our AHPbased application allowed readjustment of tradeoffs among evaluation criteria, and provided the panel members with a "more informed, transpar-

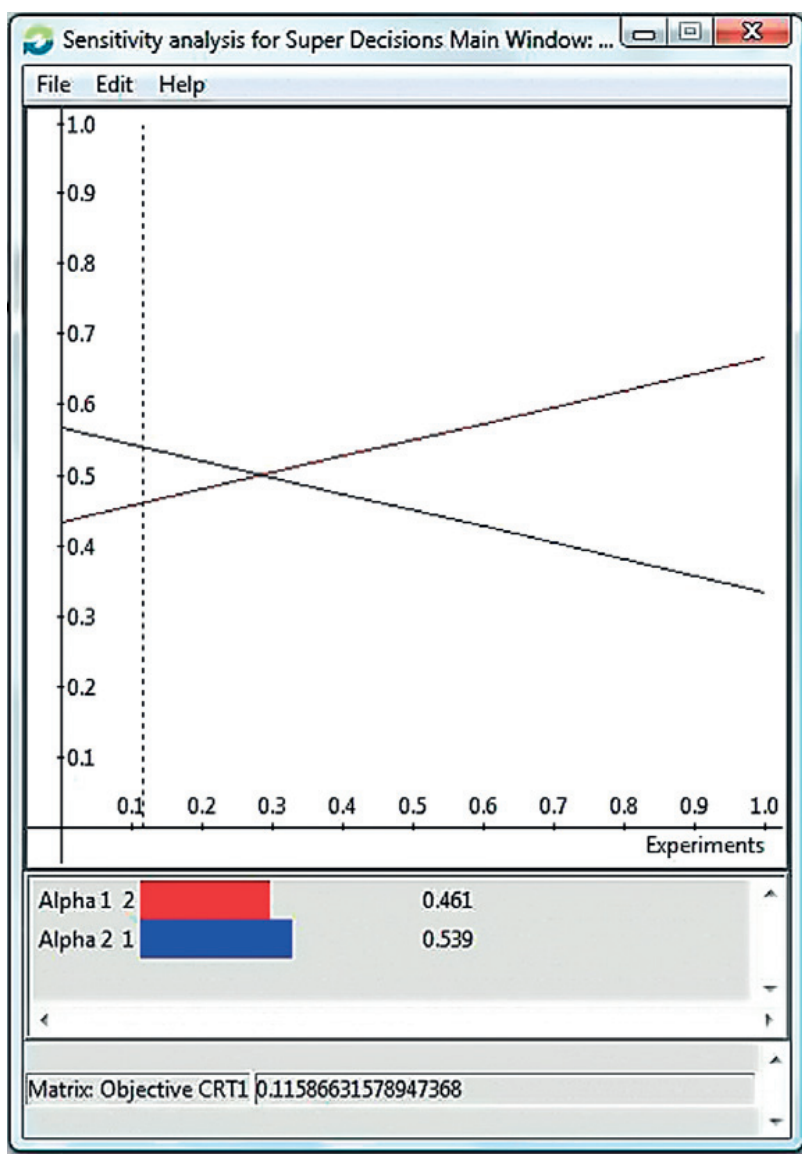

ent and accurate mortgage loan risk evaluation system" (in their own words). Our framework was additionally considered "more discerning in terms of Basel directives" (also according to the panel experts). The findings from our study suggest, therefore, that the AHP approach has the potential to enhance the existing credit scoring systems of Portuguese banking institutions. As discussed here, the AHP technique can be used to assist credit analysts in defining the relative importance of evaluation criteria, making trade-offs among them explicit. However, AHP can also be used to assist banking institutions in managing new evaluation criteria (e.g. mortgage term, property type, occupancy type).

In the current economic context it is imperative that banking institutions use comprehensive credit scoring systems in order to comply with the Basel regulatory requirements and minimize the risk of errors. It is our belief that the framework proposed here, either independently or combined with other credit classifier systems, can assist banking institutions in doing so. By allowing credit analysts to derive overall risk scores for each credit application and exploring the sensitivity of 
these scores to changes in the relative importance of the different evaluation criteria, the use of the AHP technique has the potential to lead to better informed decisions.

Despite its virtues, our proposal is not without its own shortcomings. In particular, it can be criticized on the grounds of being inherently subjective with regard to the specification of criteria weights, but also, potentially, in the choice of evaluation criteria and the scoring of credit applications. However, it is important to bear in mind that all decision-making is subjective and that the value of any MCDA based-approach is in making that subjectivity explicit and integrating it in a transparent way with objective/measurable data.

It is also important to emphasize that a nonprescriptive process-oriented position has been assumed, and because the results are contextualized and strongly dependent on the participants involved, extrapolations are discouraged unless proper adjustments take place. This may also be argued as a limitation of the proposal. Nonetheless, as previously discussed, the use of AHP also provides adjustment possibilities. On the other hand, in exploring this line of research, several other approaches can be applied, namely MACBETH Measuring Attractiveness by a Categorical Based Evaluation Technique -, MAVF - Multi-Attribute Value Function -, PAPRIKA - Potentially All Pairwise Rankings of All Possible Alternatives - or TODIM (an acronym in Portuguese of Interactive and Multicriteria Decision Making) - (for a categorized survey of different MCDA methods, see Belton, Stewart 2002; Zavadskas, Turskis 2011). Still, as suggested by Weber and Borcherding (1993) and Ananda and Herath (2009), each method has its own strengths and limitations, and there is no such thing as superior elicitation method. In fact, as is widely accepted in the MCDA literature, the choice of approach is strongly dependent on the decision context. From this premise, AHP's simplicity, solid mathematical background and ability to assess tangible and intangible factors, together with the fact that it has been applied to systematize a wide range of decision problems in different contexts, are the main reasons why it has been applied in this study. Also, as defended by Yurdakul and $\dot{I}_{c ̧}$, (2004: 286), "once properly introduced and implemented in the banks, AHP should improve their credit evaluation decision-making processes, and consequently, contribute to the success and profitability of the banks".

As complementary research, we recommend conducting: (1) a different panel study with a dif- ferent elicitation method and/or within a different banking institution; and (2) a survey of comparisons among different methodological applications. Possible improvements and/or updates will hopefully help in strengthening this line of research.

\section{ACKNOWLEDGEMENTS}

The authors gratefully acknowledge the superb contribution of the members of the panel of credit analysts: André Diogo, António Neves, Fausto Ferreira, Irina Gavancha and Paulo Pinto. We are also grateful to Professor Isabel S. Brito, Polytechnic Institute of Beja, Portugal, and to the two anonymous reviewers for the insightful comments and helpful suggestions. The second author of this paper acknowledges funding support by Fundação para a Ciência e a Tecnologia (SFRH/ BSAB/1196/2011 and FEDER/POCI2010).

\section{REFERENCES}

Akhigbe, A.; McNulty, J. 2011. Bank monitoring, profit efficiency and the commercial lending business model, Journal of Economics and Business 63(6): 531551. http://dx.doi.org/10.1016/j.jeconbus.2011.07.001

Alonso, J.; Lamata, M. 2006. Consistency in the analytic hierarchy process: a new approach, International Journal of Uncertainty, Fuzziness and Knowledge-Based Systems 14(4): 445-459. http://dx.doi. org/10.1142/S0218488506004114

Altman, E.; Saunders, A. 1997. Credit risk measurement: developments over the last 20 years, Journal of Banking \& Finance 21(11/12): 1721-1742. http:// dx.doi.org/10.1016/S0378-4266(97)00036-8

Ananda, J.; Herath, G. 2009. A critical review of multicriteria decision making methods with special reference to forest management and planning, Ecological Economics 68(10): 2535-2548. http://dx.doi. org/10.1016/j.ecolecon.2009.05.010

Avery, R.; Calem, P.; Canner, G. 2004. Consumer credit scoring: do situational circumstances matter?, Journal of Banking \& Finance 28(4): 835-856. http:// dx.doi.org/10.1016/j.jbankfin.2003.10.009

Bana e Costa, C.; Vansnick, J. 2008. A critical analysis of the eigenvalue method used to derive priorities in the AHP, European Journal of Operational Research 187(3): 1422-1428. http://dx.doi.org/10.1016/j. ejor.2006.09.022

Bana e Costa, C.; De Corte, J.; Vansnick, J. 2005. On the mathematical foundations of MACBETH, in Figueira, J.; Greco, S. and Ehrgott, M. (Eds.). Multiple criteria decision analysis: the state of the art surveys. New York: Springer, 409-442.

Belton, V.; Gear, A. 1983. On a short-coming of Saaty's method of analytic hierarchies, Omega 11(3): 228230. http://dx.doi.org/10.1016/0305-0483(83)90047-6 
Belton, V.; Stewart, T. 2002. Multiple criteria decision analysis: an integrated approach. Dordrech: Kluwer Academic Publishers.

Beltratti, A.; Stulz, R. 2012. The credit crisis around the globe: why did some banks perform better?, Journal of Financial Economics 105(1): 1-17. http://dx.doi. org/10.1016/j.jfineco.2011.12.005

Chikolwa, B.; Chan, F. 2008. Determinants of commercial mortgage-backed securities credit ratings: Australian evidence, International Journal of Strategic Property Management 12(2): 69-94. http://dx.doi. org/10.3846/1648-715X.2008.12.69-94

Costa, P.; Baidya, T. 2003. Market risk measurement methods: a comparative study, Revista Produção 13(3): 18-33.

Crook, J.; Edelman, D.; Thomas, L. 2007. Recent developments in consumer credit risk assessment, European Journal of Operational Research 183(3): 14471465. http://dx.doi.org/10.1016/j.ejor.2006.09.100

Doumpos, M.; Zopounidis, C. 2001. Assessing financial risks using a multicriteria sorting procedure: the case of country risk assessment, Omega 29(1): 97109. http://dx.doi.org/10.1016/S0305-0483(00)00028-1

Doumpos, M.; Kosmidou, K.; Baourakis, G.; Zopounidis, C. 2002. Credit risk assessment using a multicriteria hierarchical discrimination approach: a comparative analysis, European Journal of Operational Research 138(2): 392-412. http://dx.doi.org/10.1016/S03772217(01)00254-5

Ferreira, F.; Santos, S.; Rodrigues, P. 2011a. Adding value to bank branch performance evaluation using cognitive maps and MCDA: a case study, Journal of the Operational Research Society 62(7): 1320-1333. http://dx.doi.org/10.1057/jors.2010.111

Ferreira, F.; Santos, S.; Rodrigues, P. 2011b. From traditional operational research to multiple criteria decision analysis: basic ideas on an evolving field, Problems and Perspectives in Management 9(3): 114-121.

Ferreira, F.; Spahr, R.; Pereira, J. 2011c. New banking trends, MCDA and financial decisions: insights and a framework for retail banking, Banks and Bank Systems 6(2): 23-35.

Grunert, J.; Norden, L.; Weber, M. 2005. The role of nonfinancial factors in internal credit ratings, Journal of Banking \& Finance 29(2): 509-531. http://dx.doi. org/10.1016/j.jbankfin.2004.05.017

Jacobson, T.; Roszbach, K. 2003. Bank lending policy, credit scoring and value-at-risk, Journal of Banking \& Finance 27(4): 615-633. http://dx.doi.org/10.1016/ S0378-4266(01)00254-0

Kajimo-Shakantu, K.; Evans, K. 2006. The role of banks in the provision of low-income housing finance in South Africa: can they play a different role?, International Journal of Strategic Property Management 10(1): 23-38. http://dx.doi.org/10.1080/164871 5X.2006.9637542

Kaya, T.; Kahraman, C. 2011. A fuzzy approach to ebanking website quality assessment based on an integrated AHP-ELECTRE method, Technological and Economic Development of Economy 17(2): 313-334. http://dx.doi.org/10.3846/20294913.2011.583727
Kowalski, T.; Shachmurove, Y. 2011. The financial crisis: what is there to learn?, Global Finance Journal 22(3): 238-247. http://dx.doi.org/10.1016/j.gfj.2011.10.014

Laininen, P.; Hämäläinen, R. 2003. Analyzing AHPmatrices by regression, European Journal of $O p$ erational Research 148(3): 514-524. http://dx.doi. org/10.1016/S0377-2217(02)00430-7

Lima, S.; Vaz, M.; Baptista, M.; Ramos, A.; Leitão, M.; Cunha, M. 1995. Operações bancárias II. $6^{\text {th }}$ ed. Lisbon: Instituto Formação Bancária. (In Portuguese).

Lopez, J.; Saidenberg, M. 2000. Evaluating credit risk models, Journal of Banking \& Finance 24(1-2): 151165. http://dx.doi.org/10.1016/S0378-4266(99)00055-2

Mari, C.; Renò, R. 2005. Credit risk analysis of mortgage loans: an application to the Italian market, European Journal of Operational Research 163(1): 83-93. http://dx.doi.org/10.1016/j.ejor.2003.12.007

Pastor-Fernando, J.; Aragonés-Beltrán, P.; HospitalerPérez, A.; García-Melón, M. 2010. An ANP- and AHP-based approach for weighting criteria in public works bidding, Journal of the Operational Research Society 61(2): 905-916. http://dx.doi.org/10.1057/ jors. 2010.13

Perez-Gladish, B.; M'Zali, B. 2010. An AHP-based approach to mutual funds' social performance measurement, International Journal of Multicriteria Decision Making 1(1): 103-127. http://dx.doi.org/10.1504/ IJMCDM.2010.033689

Puri, M.; Rocholl, J.; Steffen, S. 2011. Global retail lending in the aftermath of the US financial crisis: distinguishing between supply and demand effects, Journal of Financial Economics 100(3): 556-578. http:// dx.doi.org/10.1016/j.jfineco.2010.12.001

Saaty, T. 1980. The analytic hierarchy process: planning, priority setting, resource allocation. New York: McGraw-Hill.

Saaty, T. 2008. Relative measurement and its generalization in decision making: why pairwise comparisons are central in mathematics for the measurement of intangible factors - the analytic hierarchy/network process, Revista de la Real Academia de Ciencias Exactas, Fisicas y Naturales. Serie A. Matematicas 102(2): 251-318. http://dx.doi.org/10.1007/ BF03191825

Scarpel, R.; Milioni, A. 2002. Utilização conjunta de modelagem econométrica e otimização em decisões de concessão de crédito, Pesquisa Operacional 22(1): 61-72. http://dx.doi.org/10.1590/S010174382002000100004

Šušteršič, M.; Mramor, D.; Zupan, J. 2009. Consumer credit scoring models with limited data, Expert Systems with Applications 36(3): 4736-4744. http:// dx.doi.org/10.1016/j.eswa.2008.06.016

Thomas, L. 2009. Modelling the credit risk for portfolios of consumer loans: analogies with corporate loan models, Mathematics and Computers in Simulation 79(8): 2525-2534. http://dx.doi.org/10.1016/j.matcom.2008.12.006

Thomas, L. 2010. Consumer finance: challenges for operational research, Journal of the Operational Research Society 61(1): 41-52. http://dx.doi.org/10.1057/ jors.2009.104 
Twala, B. 2010. Multiple classifier application to credit risk assessment, Expert Systems with Applications 37(4): 3326-3336. http://dx.doi.org/10.1016/j. eswa.2009.10.018

Vilas Boas, C. 2005. Método multicritérios de análise de decisão (MMAD) para as decisões relacionadas ao uso múltiplo de reservatórios: analytic hierarchy process (AHP), in Pessoa, J. (Ed.). Simpósio brasileiro de recursos hídricos, 6.

Wang, G.; Hao, J.; Ma, J.; Jiang, H. 2011. A comparative assessment of ensemble learning for credit scoring, Expert Systems with Applications 8(1): 223-230. http://dx.doi.org/10.1016/j.eswa.2010.06.048

Weber, M.; Borcherding, K. 1993. Behavioral influences on weight judgments in multiattribute decision making, European Journal of Operational Research 67(1): 1-12. http://dx.doi.org/10.1016/0377-2217(93)90318-H

Williams, M.; Dennis, A.; Stam, A.; Aronson, J. 2007. The impact of DSS use and information load on errors and decision quality, European Journal of Operational Research 176(1): 468-481. http://dx.doi. org/10.1016/j.ejor.2005.06.064

$\mathrm{Wu}$, H. 2012. Constructing a strategy map for banking institutions with key performance indicators of the balanced scorecard, Evaluation and Program Planning 35(3): 303-320. http://dx.doi.org/10.1016/j.evalprogplan.2011.11.009
Xiao-yan, Z.; Yan-lei, Q.; Peilong, S. 2011. Review of the international financial trends in post financial crisis era, Procedia Engineering 15: 4795-4799. http:// dx.doi.org/10.1016/j.proeng.2011.08.896

Xu, Y.; Zhang, Y. 2009. A online credit evaluation method based on AHP and SPA, Communications in Nonlinear Science and Numerical Simulation 14(7): 30313036. http://dx.doi.org/10.1016/j.cnsns.2008.10.018

Yeager, T. 2011. Causes, consequences and cures of the subprime financial crisis, Journal of Economics and Business 63(5): 345-348. http://dx.doi.org/10.1016/j. jeconbus.2011.05.004

Yu, L.; Wang, S.; Lai, K. 2009. An intelligent-agent-based fuzzy group decision making model for financial multicriteria decision support: the case of credit scoring, European Journal of Operational Research 195(3): 942-959. http://dx.doi.org/10.1016/j.ejor.2007.11.025

Yurdakul, M.; İç, Y. 2004. AHP approach in the credit evaluation of the manufacturing firms in Turkey, International Journal of Production Economics 88(3): 269-289. http://dx.doi.org/10.1016/S09255273(03)00189-0

Zavadskas, E. K.; Turskis, Z. 2011. Multiple criteria decision making (MCDM) methods in economics: an overview, Technological and Economic Development of Economy 17(2): 397-427. http://dx.doi.org/10.3846 /20294913.2011.593291 


\section{APPENDIX 1}

Evaluation criteria, descriptors and impact levels

\begin{tabular}{|c|c|c|c|c|}
\hline \multirow{2}{*}{ Criteria } & \multirow{2}{*}{ Descriptor } & \multicolumn{3}{|c|}{ Impact Levels and Partial Decisions } \\
\hline & & \multicolumn{2}{|l|}{ Impact Levels } & Decision \\
\hline \multirow{10}{*}{$\begin{array}{l}\text { Profession } \\
(12 \%)\end{array}$} & \multirow{10}{*}{ Sector: Primary, Secundary and Tertiary } & \multirow{10}{*}{ Analyzed case by case } & 1 & \multirow{5}{*}{ Favorable } \\
\hline & & & 2 & \\
\hline & & & 3 & \\
\hline & & & 4 & \\
\hline & & & 5 & \\
\hline & & & 6 & \multirow{5}{*}{ Unfavorable } \\
\hline & & & 7 & \\
\hline & & & 8 & \\
\hline & & & 9 & \\
\hline & & & 10 & \\
\hline \multirow{10}{*}{$\begin{array}{l}\text { Employment situation } \\
(8 \%)\end{array}$} & \multirow[b]{2}{*}{ Effective } & $>3$ Years & 1 & \\
\hline & & ]2; 3] Years & 2 & \\
\hline & & 2 Years & 3 & Favorable \\
\hline & Temporary & 1 Year & 4 & \\
\hline & & $<1$ Year & 5 & \\
\hline & & & 6 & \\
\hline & & & 7 & \\
\hline & Unemployed & Assumes maximum score & 8 & Unfavorable \\
\hline & & & 9 & \\
\hline & & & 10 & \\
\hline & & & 1 & \\
\hline & & & 2 & \\
\hline & & & 3 & Favorable \\
\hline & & & 4 & \\
\hline Marital status & Single Married Divorced and Widower & Analvzed case by case & 5 & \\
\hline$(3,75 \%)$ & Dingie, Mrartied, Divorced anu viluower & Anaryzed case by case & 6 & \\
\hline & & & 7 & \\
\hline & & & 8 & Unfavorable \\
\hline & & & 9 & \\
\hline & & & 10 & \\
\hline & $\leq 24$ & $\leq 24$ & 1 & \\
\hline & 25 to 35 & {$[25 ; 35]$} & 2 & \\
\hline & & [36;38] & 3 & Favorable \\
\hline & 36 to 50 & {$[39 ; 41]$} & 4 & \\
\hline Age & & {$[42 ; 50]$} & 5 & \\
\hline$(2,5 \%)$ & & {$[51 ; 60]$} & 6 & \\
\hline & & & 7 & \\
\hline & $\geq 51$ & & 8 & Unfavorable \\
\hline & & Assumes maximum score & 9 & \\
\hline & & & 10 & \\
\hline & 1 Element & 1 & 1 & \\
\hline & & 2 & 2 & \\
\hline & 2 to 4 Elements & 3 & 3 & Favorable \\
\hline & 2 to 4 Elements & 4 & 4 & \\
\hline Household & & 2 to 4 with ascendants & 5 & \\
\hline$(3,75 \%)$ & & 5 & 6 & \\
\hline & & $>6$ ascendants & 7 & \\
\hline & $\geq 5$ Elements & -o ascentiants & 8 & Unfavorable \\
\hline & & $>6$ ascendants and descen- & 9 & \\
\hline & & & 10 & \\
\hline & Customer who holds several financial products & & $\frac{1}{2}$ & \\
\hline & and households his/her salary in the institution & Depends on the typology of & 3 & Favorable \\
\hline & Customer who holds a single bank account and & & 4 & \\
\hline Cross-selling & households his/her salary & & 5 & \\
\hline$(10 \%)$ & & & 6 & \\
\hline & Customer who does not have any relationshin & & 7 & \\
\hline & $\begin{array}{l}\text { Customer who does not have any relationship } \\
\text { with the institution }\end{array}$ & Assumes maximum score & 8 & Unfavorable \\
\hline & & & 9 & \\
\hline & & & 10 & \\
\hline & $\geq 100.000 €$ & & 1 & \\
\hline & $\overline{5} 0.001$ to $100.000 €$ & & 2 & \\
\hline & 25.000 to $50.000 €$ & & 3 & Favorable \\
\hline & 2.500 to $24.999 €$ & ] $12.500 ; 25.000[$ & 4 & \\
\hline Deposit portfolio & $2.5000024 .999 t$ & {$[2.500 ; 12.500]$} & 5 & \\
\hline$(2,5 \%)$ & & & 6 & \\
\hline & & & 7 & \\
\hline & $<2.500 €$ & Assumes maximum score & 8 & Unfavorable \\
\hline & & & 9 & \\
\hline & & & 10 & \\
\hline
\end{tabular}




\begin{tabular}{|c|c|c|c|c|}
\hline \multirow{10}{*}{$\begin{array}{l}\text { Average balances } \\
(2,5 \%)\end{array}$} & \multirow{2}{*}{$>1.000 €$} & $>2.500$ & 1 & \multirow{5}{*}{ Favorable } \\
\hline & & [1.0001 2.500] & 2 & \\
\hline & \multirow{3}{*}{0 to $1000 €$} & {$[501 ; 1.000]$} & 3 & \\
\hline & & {$[251 ; 500]$} & 4 & \\
\hline & & {$[0 ; 250]$} & 5 & \\
\hline & \multirow{5}{*}{$\begin{array}{l}<0 € \\
\text { (There is salary household) }\end{array}$} & {$[-500 ;-1]$} & 6 & \multirow{5}{*}{ Unfavorable } \\
\hline & & {$[-1.499 ;-501]$} & 7 & \\
\hline & & {$[-1.999 ;-1.500]$} & 8 & \\
\hline & & {$[-3.000 ;-2.000]$} & 9 & \\
\hline & & $<-3.000$ & 10 & \\
\hline \multirow{10}{*}{$\begin{array}{l}\text { Rate of effort } \\
(15 \%)\end{array}$} & \multirow{10}{*}{0 to $100 \%$} & {$[0 ; 30[$} & 1 & \multirow{5}{*}{ Favorable } \\
\hline & & {$[31 ; 60[$} & 2 & \\
\hline & & {$[61 ; 90[$} & 3 & \\
\hline & & [90;99] & 4 & \\
\hline & & \multirow{6}{*}{$\begin{array}{l}>100 \\
\text { Assumes maximum score }\end{array}$} & 5 & \\
\hline & & & 6 & \multirow{5}{*}{ Unfavorable } \\
\hline & & & 7 & \\
\hline & & & 8 & \\
\hline & & & 9 & \\
\hline & & & 10 & \\
\hline \multirow{10}{*}{$\begin{array}{l}\text { Responsabities in BP } \\
(15 \%)\end{array}$} & Without responsibilities (age indexed) & & 1 & \\
\hline & & Equivalent to 0\% (bond) & 2 & \\
\hline & & Equivalent to $10 \%$ & 3 & Favorable \\
\hline & (rate of effort indexed) & Equivalent to $20 \%$ & 4 & \\
\hline & & $>30 \%$ & 5 & \\
\hline & & & 6 & \\
\hline & & & 7 & \\
\hline & With responsibilities and incidents & Implies automatic rejection & 8 & Unfavorable \\
\hline & & & 9 & \\
\hline & & & 10 & \\
\hline & & {$[0 ; 20[$} & 1 & \\
\hline & & {$[21 ; 40[$} & 2 & \\
\hline & $<89 \%$ & {$[41 ; 60[$} & 3 & Favorable \\
\hline & & {$[61 ; 80[$} & 4 & \\
\hline LTV & & {$[81 ; 89[$} & 5 & \\
\hline$(15 \%)$ & & {$[90 ; 100]$} & 6 & \\
\hline & & & 7 & \\
\hline & $\geq 90 \%$ & & 8 & Unfavorable \\
\hline & & $>100$ & 9 & \\
\hline & & & 10 & \\
\hline & & & 1 & \\
\hline & & & 2 & \\
\hline & Yes & Analyzed case by case & 3 & Favorable \\
\hline & & & 4 & \\
\hline Existence of guarantors & & & 5 & \\
\hline$(5 \%)$ & & & 6 & \\
\hline & & & 7 & \\
\hline & No & Analyzed case by case & 8 & Unfavorable \\
\hline & & & 9 & \\
\hline & & & 10 & \\
\hline & & & 1 & \\
\hline & & Depends on the conjuncture & 2 & \\
\hline & Stable & & 3 & Favorable \\
\hline & & Stable with difficulties & 4 & \\
\hline $\begin{array}{l}\text { Economic situation of the } \\
\text { country }\end{array}$ & & Stable with difficulties & 5 & \\
\hline$(2,5 \%)$ & & & 6 & \\
\hline & & & 7 & \\
\hline & Unstable & Assumes maximum score & 8 & Unfavorable \\
\hline & & & 9 & \\
\hline & & & 10 & \\
\hline & & & 1 & \\
\hline & & Depends on the conjuncture & 2 & \\
\hline & Stable & & 3 & Favorable \\
\hline Political situation of the & & Stable with difficulties & 4 & \\
\hline country & & & 5 & \\
\hline$(2,5 \%)$ & & & 6 & \\
\hline & & & 7 & \\
\hline & Unstable & Assumes maximum score & 8 & Unfavorable \\
\hline & & & $\begin{array}{l}9 \\
10\end{array}$ & \\
\hline
\end{tabular}

